\title{
ANALISIS SIFAT KEKUATAN TARIK DAN KEKUATAN BENDING KOMPOSIT HIBRYD SERAT LIDAH MERTUA DAN KARUNG GONI DENGAN FILLER ABU SEKAM PADI 5\% BERMATRIK EPOXY
}

\author{
Jauhari Muslim, Nasmi Herlina Sari, Emmy Dyah \\ Jurusan Teknik Mesin Fakultas Teknik Universitas Mataram \\ JIn. Majapahit No.62 Mataram Nusa Tenggara Barat Kode Pos: 83125 \\ Telp. (0370) 636087; 636126; ext 128 Fax (0370) 636087
}

\begin{abstract}
The use of composite materials is growing at over the development of manufacturing industry. Composites sansevieria and hibiscus canabinus with the addition of rice husk ash filler. The purpose of this study was to analyze the tensile strength and bending strength of hybrid composites sansevieria and hybiscus canabinus with rice husk ash filler epoxy bermatrik with random fiber direction.

Variation of fiber volume fraction sansevieria and hybicus canabinus is 0\%:35\%,10\%:25\%, 15\%:10\%, 20\%:15\%, 25\%:10\%, 35\%:0\%. Method for making composite specimens in the form of hand lay up with a fiber length of $2 \mathrm{~cm}$. Testing was done by bending test following the ASTM standard D790 tensile test and ASTM D3039 standards.

The results showed that the composites with rice husk ash fillers higher bending strength and the strength of its appeal compared to the composite without using rice husk ash fillers, where the highest bending strength on volume fraction $0 \% / 35 \%$ as big as 32,00 $\mathrm{MPa}$ (using filler), and kekutan lowest bending the volume fraction 0\%/35\% as big as 21, $69 \mathrm{Mpa}$ (without filler). While the tensile test has the highest power in the volume fraction $15 \% / 20 \%$ as big as $8,24 \mathrm{MPa}$ (using filler), and the lowest tensile strength on volume fraction $0 \% / 35 \%$ as big as $3,43 \mathrm{MPa}$ (without filler).
\end{abstract}

Keywords: Tensile strength, bending strength, Sansevieria, Hybicus canabinus, Rice husk ash filler, epoxy.

\section{PENDAHULUAN}

Penggunaan dan pemanfaatan komposit dewasa ini terus menerus dikembangkan didalam industri manufacture. Salah satunya material komposit yang diharapkan di dunia industri yaitu material komposit dengan material pengisi/filler baik yang berupa serat alami maupun serat buatan. Saat ini bahan komposit yang diperkuat dengan serat merupakan bahan teknik yang banyak digunakan karena kekuatan dan kekakuan spesifik yang jauh di atas bahan teknik pada umumnya, sehingga sifatnya dapat didesain mendekati kebutuhan.

Bahan komposit hybrid merupakan gabungan antara type serat lurus dengan serat acak, dengan pertimbangannya supaya dapt mengeliminir kekurangan sifat dari kedua type dan menggabungkan kelebihannya Penggunaan sistem hybrid di dalam teknologi komposit pada saat ini sangat berkembang pesat. Menurut Richardson (1987). komposit yang dihasilkan dari dua atau lebih bahan pengisi ataupun matriks yang berlainan. Jadi pengisi limbah padat campuran organik dengan anorganik pada mikrokomposit disebut dengan komposit hybrid.

Lidah mertua adalah tumbuhan yang tumbuh menahun (perennial). Meskipun bukan tanaman asli Indonesia, lidah mertua ini telah ada sejak puluhan tahun lalu. Pada awalnya, lidah mertua yang mulai dikenal secara luas dan. Mengingat kualitas seratnya yang baik, maka tumbuhan ini mulai dibudidayakan. Serat lidah mertua (Sansevieria) adalah marga tanaman hias yang cukup popular sebagai penghias bagian dalam rumah karena tanaman ini dapat tumbuh dalam kondisi yang sedikit air dan cahaya matahari. Selain sebagai penyerap racun lidah mertua digunakan sebagai bahan baku serat pada industri textil.

Pemanfaatan karung goni sebagai bahan komposit merupakan langkah yang 
baik guna meningkatkan fungsinya yang selama ini hanya digunakan sebagai karung pembungkus. Pengembangan riset dan teknologi dengan memanfaatkan produk lokal merupakan langkah bijak untuk meningkatkan nilai jual material lokal. Menurut Diharjo, dkk (2005) pengaruh perlakuan alkali 2 jam pada serat kenaf memberikan kekuatan tarik paling tinggi dibandingkan dengan perlakuan alkali 0, 4, 6 dan 8 jam. Febriyanto dan Diharjo (2004) telah meneliti kekuatan bending komposit dari karung goni yaitu 13,87 MPa.

Resin epoxy memiliki berbagai keunggulan sebagai zat perekat dibandingkan dengan polimer-polimer yang lain. Diantaranya adalah keaktifan permukaan tinggi, daya pembasahan baik, kekuatan kohesif tinggi, tidak mengkerut, dapat luwes diubah-ubah sifatnya dengan memilih resin hardener yang tepat. Perekat epoxy kekuatannya tidak berubah dalam waktu yang lama, tahan minyak, gemuk, panas atau cuaca dingin.

Dari sumber informasi diatas mengindikasikan bahwa perlu dilakukan penelitian mengenai komposit hybrid dengan memadukan serat lidah mertua dan karung goni sebagai penguat dan memasukkan filler abu sekam padi sebesar $5 \%$ bermatrik epoxy.

Tujuan dari penelitian ini adalah untuk menganalisis sifat kekuatan tarik dan bending komposit hybrid serat lidah mertua dan karung goni dengan dan tanpa menggunakan filler abu sekam padi dengan matrik resin epoxy.

Adapun manfaat yang diharapkan dari penelitian ini adalah untuk memberikan informasii tentang komposit lidah mertua dan karung goni dengan menggunakan filler abu sekam padi dan tanpa penambahan filler abu sekam padi dengan variasi fraksi volume $0 \% / 35 \%, \quad 10 \% / 25 \%, \quad 15 \% / 20 \%$, $20 \% / 15 \%, 25 \% / 10 \%, 35 \% / 0 \%$ terhadap kekuatan tarik dan kekuatan bending komposit

\section{LANDASAN TEORI}

Material komposit yang dibuat menggunakan serat kenaf dan matrik polyester resin. Dalam penelitian diperoleh hasil bahwa komposit serat kenaf-polyester resin dengan fraksi volume bertambah diperoleh hasil tegangan bending yang tinggi pula. Jadi bila semakin besar fraksi volumenya semakin besar pula kekuatannya. Purwanto (2006). Dalam penelitian Mohammad Romi (2003) yang temannya membandingkan serat kontinyu dan serat acak dengan matrik polyester diperoleh hasil kekuatan tarik kontinyu lebih besar dari kekuatan tarik acak. Dengan demikian diharapkan pada pengujian yang akan dilakukan dengan serat, matrik, dan cara yang berbeda diperoleh hasil yang lebih baik dari pengujian yang sebelumnya.

Pengaruh lama perlakuan alkali terhadap kekuatan tarik komposit serat kenaf dengan lama perlakuan 0, 2, 4, 6 dan 8 jam. Berdasarkan penelitiannya dapat disimpulkan bahwa perlakuan alkali selama 2 jam menghasilkan kekuatan tarik dan modulus elastisitas paling tinggi. besarnya modulus elastisitas dan kekuatan tarik serat kenaf adalah $53 \mathrm{GPa}$ dan $930 \mathrm{MPa}$, dan regangan maksimumnya $1,6 \%$ besarnya density serat adalah $1,4 \mathrm{gr} / \mathrm{cm}^{3}$. Penggunaan abu sekam padi sebagai filler pada komposit bermatrik polypropylene dipelajari oleh Siriwardena,S.dkk (2003).

Komposit merupakan sejumlah sistem multifasa sifat gabungan, yaitu gabungan antara bahan matrik atau pengikat dengan penguat unsur utama. Bahan komposit adalah serat karena serat menentukan karakteristik bahan komposit seperti kekakuan, kekuatan serta sifat-sifat mekanik yang lain. Matrik bertugas melindungi dan mengikat serat agar dapat bekerja dengan baik, dan meneruskan gaya dari suatu serat ke serat lain. Matrik dapat berupa keramik dan logam di samping berupa polimer.

Secara umum, dikenal tiga kelompok komposit, yaitu:

a. Komposit berserat yaitu komposit berpenguat serat antara lain seperti, serat gelas (fiber glass), serat karbon, serat grafit sampai serat baja.

b. Komposit laminer atau laminat yaitu komposit berpenguat dalam bentuk lembaran seperti kertas, kain.

c. Komposit partikel atau partikulat yaitu komposit berpenguat dalam bentuk butiran seperti kerikil, pasir, filler dalam bentuk kontinyu.

Dalam hal polimer diperkuat serat, ada zat ketiga yang disebut zat penjodoh, penggabungan atau penyerasi untuk meningkatkan sekatan antara serat dan matrik. (Feldman. D., Dkk, 1995). 
Untuk memperoleh komposit yang kuat harus dapat menempatkan serat dengan benar. Berdasarkan penempatannya terdapat beberapa tipe serat pada komposit, yaitu

1. Continuous Fiber Composite

Continuous atau uni-directional, mempunyai susunan serat panjang dan lurus, membentuk lamina diantara matriknya. Jenis komposit ini paling sering digunakan. Tipe ini mempunyai kelemahan pada pemisahan antar lapisan. Hal ini dikarenakan kekuatan antar lapisan dipengaruhi oleh matriknya.

2. Woven Fiber Composite (bi-dirtectional) Komposit ini tidak mudah dipengaruhi pemisahan antar lapisan karena susunan seratnya juga mengikat antar lapisan. Akan tetapi susunan serat memanjangnya yang tidak begitu lurus mengakibatkan kekuatan dan kekakuan akan melemah.

3. Discontinuous Fiber Composite

Discontinuous Fiber Composite adalah tipe komposit dengan serat pendek. Tipe ini dibedakan lagi menjadi 3:

$\checkmark$ Aligned discontinuous fiber

$\checkmark$ Off-axis aligned discontinuous fiber

$\checkmark$ Randomly oriented discontinuous fiber

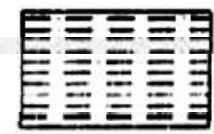

(a) aligned

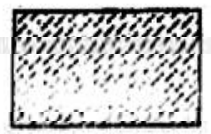

(b) off-axis

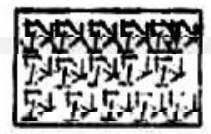

(c) randomly
Gambar 1. Tipe discontinuous fiber

(Sumber: Gibson, 1994)

Tipe acak sering digunakan pada produksi dengan volume besar karena faktor biaya manufakturnya yang lebih murah. Kekurangan dari jenis serat acak adalah sifat mekanik yang masih dibawah dari penguatan dengan serat lurus pada jenis serat yang sama.

4. Hybrid Fiber Composite

Hybrid fiber composite merupakan komposit gabungan antara tipe serat lurus dengan serat acak. Tipe ini digunakan supaya dapat menganti kekurangan sifat dari kedua tipe dan dapat menggabungkan kelebihannya.

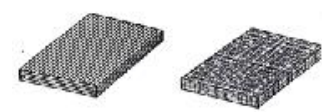

(a)

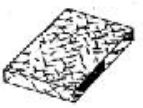

(c)

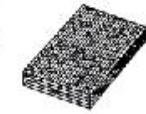

(d)
Gambar 2. Tipe komposit serat (a) Continuous Fiber Composite, (b) Woven Fiber Composite, (c) Randomly oriented discontinuous fiber, (d) Hybrid fiber composite. (courteney, 1999)

Penelitian yang mengabungkan antara matrik dan serat harus memperhatikan beberapa faktor yang mempengaruhi performa Fiber-Matrik Composites antara lain:

1. Faktor serat

Serat adalah bahan pengisi matrik yang digunakan untuk dapat memperbaiki sifat dan struktur matrik yang tidak dimilikinya, juga diharapkan mampu menjadi bahan penguat matrik pada komposit untuk menahan gaya yang terjadi.

2. Letak Serat

Dalam pembuatan komposit tata letak dan arah serat dalam matrik yang akan menentukan kekuatan mekanik komposit, dimana letak dan arah dapat mempengaruhi kinerja komposit tersebut.

Menurut tata letak dan arah serat diklasifikasikan menjadi 3 bagian yaitu:

$\checkmark$ One dimensional reinforcement, mempunyai kekuatan dan modulus maksimum pada arah axis serat.

$\checkmark$ Two dimensional reinforcement (planar), mempunyai kekuatan pada dua arah atau masing-masing arah orientasi serat.

$\checkmark$ Three dimensional reinforcement, mempunyai sifat isotropic kekuatannya lebih tinggi dibanding dengan dua tipe sebelumnya.

Pada pencampuran dan arah serat mempunyai beberapa keunggulan, jika orientasi serat semakin acak (random) maka sifat mekanik pada satu arahnya akan melemah, bila arah tiap serat menyebar maka kekuatannya juga akan menyebar kesegala arah maka kekuatan akan meningkat.

3. Panjang Serat

Panjang serat dalam pembuatan komposit serat pada matrik sangat berpengaruh terhadap kekuatan. Serat panjang lebih kuat dibanding serat pendek.

4. Bentuk serat

Pada umumnya, semakin kecil diameter serat akan menghasilkan kekuatan komposit yang lebih tinggi. Selain bentuknya kandungan seratnya juga mempengaruhi

Untuk mengetahui kekuatan bending dapat dilakukan pengujian dengan mesin uji Torsee. Pada pengujian bending, bagian atas spesimen akan mengalami tegangan tekan 
dan bagian bawah akan mengalami tegangan tarik. Kekuatan bending suatu material dapat dihitung dengan persamaan berikut:

$$
\sigma_{b}^{n}=\frac{l}{\text { lengan be }} \frac{3 P_{L}}{2 b d \overline{2}}
$$

Keterangan:

$$
\begin{aligned}
\sigma_{b} & =\text { Kekuatan bending (MPa) } \\
\mathrm{P} & =\text { Beban (MPa) } \\
\mathrm{L} & =\text { Panjang span }(\mathrm{mm}) \\
\mathrm{b} & =\text { Lebar batang uji }(\mathrm{mm}) \\
\mathrm{d} & =\text { Tebal batng uji }(\mathrm{mm})
\end{aligned}
$$

\section{METODE PENELITIAN}

Alat yang digunakan dalam penelitian ini adalah mesin uji bending, cetakan/alat pengepres, timbangan, gelas ukur dan suntikan, gelas pencampur/ tempat pencampur dan alat pengaduk, jangka sorong/mistar dan busur derajat, silet kater/pisau, sikat kawat

Adapun bahan dalam penelitian ini antara lain resin epoxy, serat lidah mertua, serat karung goni larutan $\mathrm{NaOH}$ dengan konsentrasi larutan 4\%, air mineral,wax mold release atau kit mobil.

Perlakuan alkali serat dangan larutan $\mathrm{NaOH} 4 \%$ selama 2 jam. Benda uji dibuat dengan serat lidah mertua dan serat karung goni sebagai penguat dan resin epoxy sebagai matrik. Bentuk spesimen komposit hybrid adalah plat dengan resin plyester $60 \%$ (tetap) dan 65\%(tetap) fraksi volume serat lidah mertua/serat karung goni masingmasing $0 \% / 35 \%, \quad 10 \% / 25 \%, \quad 15 \% / 20 \%$, $20 \% / 15 \%, 25 \% / 10 \%$, 35\%/0\%. Benda uji dibuat dengan cara hand lay up dan dengan penekanan secara manual mengunakan kaca sebagai cetakan dan penekan. Pengujian komposit berupa uji bending dan uji tarik dilaksanakan dii Laboratorium Geoteknik Teknik Sipil Fakultas Teknik Universitas Mataram dan di Laboratorium produksi Teknik Mesin Fakultas Universitas udayana Langkah-langkah yang dilakukan dalam pembuatan komposit yaitu sebagai berikut:

1. Alat dan bahan dipersiapkan dahulu.

2. Serat dipotong terlebih dahulu dengan ukuran $2 \mathrm{~cm}$.

3. Serat ditimbang dengan menggunakan timbangan digital untuk mendapatkan berat serat yang dibutuhkan.

4. Proses Hand Lay Up

Cetakan yang sudah siap dipakai di atasnya diberikan serat yang mana disusun secara gambar dibawah ini. Selanjutnya diberikan resin sampai batas yang di hendaki.

5. Tahap awal yaitu pengolesan kit mobil pada cetakan untuk memudahkan pengambilan benda uji dari cetakan

6. Tuangkan resin epoxy dan abu sekam padi sesuai perhitungan yang telah ditentukan kedalam gelas pencampur, kemudian aduk hinggaa campuran tersebut merata.

7. Tuangkan resin epoxy dan abu sekam padi didalam cetakan, setelah itu taburkan serat lidah mertua dan karung goni sesuai fraksi volume yang telah ditentukan.

8. Tuangkan kembali resin epoxy dan abu sekam padi diatas serat tersebut.

9. Penutupan dengan menggunakan kaca yang bertujuan meminimalkan terjadinya void, kemudian dilakukan pengepresan dengan menggunakan beban penekan.

10. Proses pengeringan dilakukan dibawah sinar matahari, proses ini dilakukan sampai benar benar kering yaitu $5-10$ jam.

11. Proses pengambilan komposit dari cetakan yaitu menggunakan pisau/ cutter.

12. Finishing, memotong spesimen sesuai standar yang sudah ditentukan.

Komposit yang telah dicetak dibentuk menjadi benda uji sesuai dengan standar spesimen uji bending. Dimensi spesimen uji bending dapat dilihat pada gambar dibawah ini.

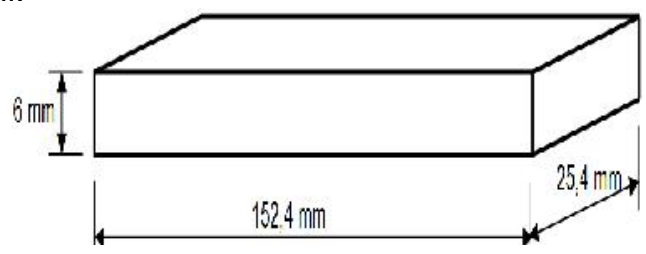

Gambar 3. Spesimen uji bending ASTM D790 (Sumber: Gibson, 1994)

Pada uji bending, spesimen yang berbentuk batang ditempatkan pada dua tumpuan lalu diberikan beban ditengah tumpuan tersebut dengan laju pembebanan konstan sampai spesimen mengalami patah atau retak. 


\section{HASIL DAN PEMBAHASAN Uji Bending.}

Pengujian bending dilakukan menggunakan alat uji bending dengan merk Torsee Universal Testing Machine tipe AMU5-DE. Pada penelitian ini dilakukan di laboratorium Struktur dan Beton Teknik Sipil. Data hasil uji bending yang diambil merupakan kekuatan bending rata-rata dari tiga spesimen. Data-data dari pengujian kemudian dimasukkan dalam persamaan 2.4 sehingga diperoleh besarnya kekuatan bending seperti pada tabel berikut :

\begin{tabular}{|c|c|c|c|c|c|}
\hline \multirow{2}{*}{\multicolumn{2}{|c|}{\begin{tabular}{|} 
Fraksi Volume \\
Serat $(\%)$
\end{tabular}}} & \multirow{2}{*}{\multicolumn{3}{|c|}{$\begin{array}{c}\text { Kekuatan Bending Skin } \\
(\mathrm{MPa})\end{array}$}} & \multirow[t]{3}{*}{$\begin{array}{l}\text { Kekuatan } \\
\text { rata-rata }\end{array}$} \\
\hline & & & & & \\
\hline $\begin{array}{c}\text { Lidah } \\
\text { mertua }\end{array}$ & $\begin{array}{c}\text { Karung } \\
\text { goni }\end{array}$ & 1 & 2 & 3 & \\
\hline 0 & 35 & 20,5 & 19,85 & 24,73 & 21,69 \\
\hline 10 & 25 & 23,1 & 22,9 & 24,05 & 23,25 \\
\hline 15 & 20 & 27,66 & 22,45 & 20,83 & 23,65 \\
\hline 20 & 15 & 25,38 & 31,9 & 29,61 & 28,96 \\
\hline 25 & 10 & 25,05 & 23,43 & 32,55 & 27,01 \\
\hline 35 & 0 & 19,85 & 21,8 & 25,05 & 22,23 \\
\hline
\end{tabular}

\begin{tabular}{|c|c|c|c|c|c|c|}
\hline \multirow{3}{*}{$\begin{array}{l}\text { Abu } \\
\text { Sekam } \\
\text { Padi }\end{array}$} & \multirow{2}{*}{\multicolumn{2}{|c|}{$\begin{array}{l}\text { Fraksi Volume } \\
\text { Serat }(\%)\end{array}$}} & \multirow{2}{*}{\multicolumn{3}{|c|}{\begin{tabular}{|c}
$\begin{array}{c}\text { Kekuatan Bending Skin } \\
(\mathrm{MPa})\end{array}$ \\
Pengulangan
\end{tabular}}} & \multirow{3}{*}{$\begin{array}{l}\text { Kekuatan } \\
\text { rata-rata }\end{array}$} \\
\hline & & & & & & \\
\hline & \multicolumn{2}{|c|}{\begin{tabular}{|c|c|} 
Lidah & Karung \\
mertua & goni \\
\end{tabular}} & 1 & 2 & 3 & \\
\hline \multirow{6}{*}{$5 \%$} & 0 & 35 & 31,25 & 34,5 & 30,26 & 32,00 \\
\hline & 10 & 25 & 25,38 & 35,8 & 31,9 & 31,03 \\
\hline & 15 & 20 & 27,66 & 35,8 & 28,63 & 30,7 \\
\hline & 20 & 15 & 27,33 & 30,26 & 31,9 & 29,83 \\
\hline & 25 & 10 & 28,31 & 26,03 & 26,68 & 27,01 \\
\hline & 35 & 0 & 24,4 & 26,03 & 26,33 & 25,58 \\
\hline
\end{tabular}

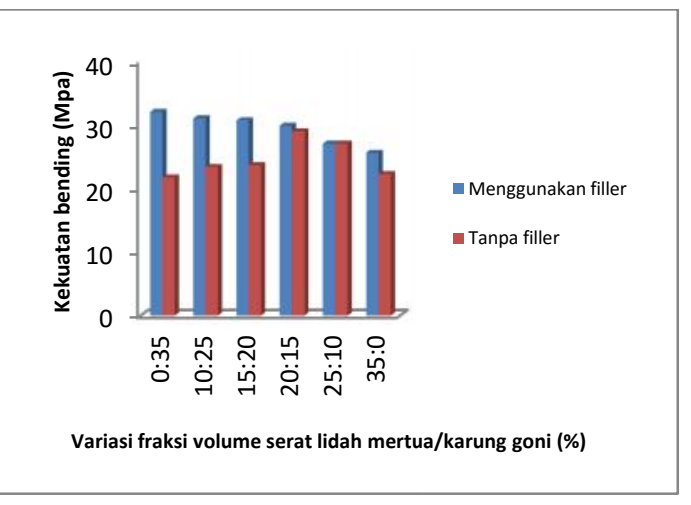

Grafik 4.1 hubungan kekuatan bending dengan variasi fraksi volume serat lidah mertua dan karung goni pada komposit epoxy.
Kekuatan bending menggunakan filler, dengan perbandingan variasi fraksi serat lidah mertua dan serat karung goni 0:35 (\% volume) memiliki kekuatan bending tertinggi sebesar 32,00 MPa, dibandingkan dengan variasi fraksi volume serat lidah mertua dan serat karung goni 10:25 (\% volume) didapat kekuatan bending-nya sebesar 31,03 MPa dengan persentase penurunan $97,78 \%$, pada variasi fraksi volume serat lidah mertua dan serat karung goni 15:20 (\% volume), didapat kekuatan bending-nya sebesar 30,7 MPa, dengan persentase penurunan sebesar $32,78 \%$, selanjutnya pada variasi serat lidah mertua dan serat karung goni 20:15 (\% volume) kekuatan bending-nya sebesar 29,83 MPa, persentase penurunan $86,67 \%$, untuk variasi serat lidah mertua dan serat karung goni 25:10 (\% volume) kekuatan bending-nya sebesar 26,03 MPa, dengan persentase penurunan $282,2 \%$, selanjutnya dengan perbandingan serat lidah mertua dan karung goni 35:0 (\%volume) di dapat kekuatan bending terendah sebesar 25,58 $\mathrm{MPa}$, dengan persentase penurunan 142,2 \%. Kekuatan bending tanpa menggunakan filler, dengan perbandingan variasi fraksi volume serat lidah mertua dan serat karung goni 0:35 (\% volume) memiliki kekuatan bending-nya sebesar 21,69 MPa, dibandingkan dengan variasi fraksi volume serat lidah mertua dan serat karung goni 10:25 (\% volume) didapat kekuatan bendingnya sebesar 23,25 MPa dengan persentase kenaikan $165,6 \%$. Pada variasi fraksi volume serat lidah mertua dan serat karung goni 15:20 (\% volume), didapat kekuatan bendingnya sebesar 23,65 $\mathrm{MPa}$, terjadi kenaikan sebesar $30 \%$, selanjutnya pada variasi serat lidah mertua dan serat karung goni 20:15 (\% volume) memiliki kekuatan bending tertinggi sebesar 28,96 MPa, dengan kenaikan persentase $531,7 \%$. Pada variasi fraksi volume serat lidah mertua dan serat karung goni 25:10 (\% volume) didapat kekuatan bending-nya sebesar 27,01 $\mathrm{MPa}$, dengan penurunan persentase $195,6 \%$, selanjutnya dengan perbandingan serat lidah mertua dan karung goni 35:0 (\%volume) di dapat kekuatan bending-nya terendah sebesar $25,58 \mathrm{MPa}$, dengan penurunan persentase $477,8 \%$.

Pengujian bending adalah komposit akan mengalami retak pada bagian bawah karena tidak mampu menahan tegangan tarik 
yang terjadi. Hal ini menunjukkan bahwa gaya tarik yang terjadi akibat pembebanan bending sangat besar. Gambar bentuk patahan spesimen uji bending dapat dilihat pada gambar dibawah ini:

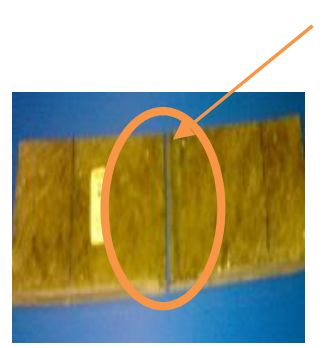

patahan

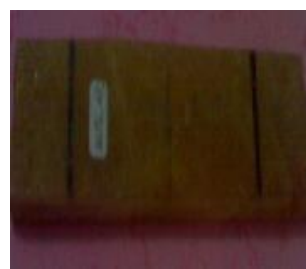

Gambar 4.1 Patahan spesimen uji bending komposit epoxy dengan variasi serat lidah mertua dan karung goni (0\%:35\%).

Dengan filler. (b). Tanpa filler.

Gambar 4.1 menunjukan kekuatan bending rata-rata komposit dengan perbandingan fraksi volume serat lidah mertua dan serat karung goni (0\%:35\%) dan menggunakan filler, adalah $32,00 \mathrm{MPa}$. Adanya filler mempengaruhi kekuatan spesimen dan fraksi volume serat lidah mertua dan karung goni tersebar merata, namun kekuatan bendingnya lebih rendah dari pada perbandingan serat lidah mertua dan serat karung goni (0\%:35\%) tanpa filler disini sifat spesimennya bersifat ulet. Hal ini dapat disebabkan karena pada saat pembuatan spesimen dan pengaruh suhu pengeringannya.

\section{KESIMPULAN}

Hasil dari penelitian komposit serat lidah mertua dan karung goni dengan menggunakan filler abu sekam padi dan tanpa menggunakan filler abu sekam padi menunjukkan bahwa komposisi dengan menggunakan filler abu sekam padi lebih tinggi dibandingkan dengan tanpa filler abu sekam padi.

Kekuatan bending pada variasi fraksi volume menggunakan filler 0:35, 10:25, $15: 20, \quad 20: 15, \quad 25: 10, \quad 35: 0$ (\% volume) mengalami penurunan tetapi kekuatan bending-nya diatas rata-rata yang tanpa menggunakan filler dan dimana kekuatan bending tanpa menggunakan filler yang mengalami kenaikan pada variasi fraksi volume 0:35, 10:25, 15:20, 20:15 (\% volume) dan pada variasi fraksi volume 25:10, 35:0 (\% volume) mengalami penurunan. Kekuatan tarik pada variasi fraksi volume menggunakan filler 0:35, 10:25, 15:20 (\% volume) mengalami kenaikan dan pada variasi fraksi volume 20:15, 25:10, 35:0 (\% volume) mengalami penurunan dan dimana kekuatan tarik tanpa menggunakan filler yang mengalami kenaikan pada variasi fraksi volume $0: 35,10: 25,15: 20,20: 15$ 25:10 (\% volume) dan pada variasi fraksi volume 35:0 (\% volume) mengalami penurunan.

\section{SARAN}

Berdasarkan penelitian yang telah dilakukan maka beberapa saran dapat diberikan guna penelitian selanjutnya yaitu:

1. Resin epoxy setelah dicampur dengan katalis akan sangat kental dan cepat mengeras, untuk itu penuangan filler kedalam resin,dan penuangan resin yang sudah bercampur filler kedalam serat harus dilakukan dengan cepat agar resin dapat menyebar merata ke serat.

2. Penekanan pada saat pencetakan harus dilakukan secara merata agar cetakan terisi dengan resin secara menyeluruh, sehingga dapat mengurangi terjadinya void.

3. Untuk mendapatkan hasil pengujian komposit yang akurat, hal yang sangat perlu diperhatikan yaitu proses pada tahap pembuatan spesimen komposit tersebut serta pengkalibrasian alat-alat yang digunakan.

\section{DAFTAR PUSTAKA}

Bismarck, A., Askargorta, I.A., Lamphe, T., Wielaye, B., Stamboulis, A., Skenderovich, I., Limbach, H.H., 2006, Surface Characterization of Flax, Hemp and Cellulose Fibres: Surface Properties and the Water Uptake Behavior, Polymer Composite Vol 23, no. 5.

Budinski, Kenneth., 2000, Engineering Materials Properties and Selection sixth Edition, Prentice Hall, New Jersey.

Dharma Putra,2006. Jurnal ilmiah teknik sipil vol 10, no 2, Universitas udayana

Diharjo, K., 2005, Pengaruh Perlakuan Alkali terhadap Sifat Tarik Bahan Komposit Serat Rami-Polyester, Jurnal Teknik Mesin Fakultas 
Teknik Universitas Negeri Sebelas Maret, Surakarta

Febrianto, 2004, Menyelidiki kekuatan bending dan impak komposit hibrid sandwich kombinasi serat karung Goni dan serat Gelas-polyester dengan core kayu Sengon Laut (Albizzia Falcata).

Feldman. D., dan Hatomo, J.A., 1995, Bahan Polimer Konstruksi Bangunan, Gramedia Pustaka Utama.

Gibson, F.R., 1994, Principle of Composite Material Mechanis, International Edition, McGraw-Hill Inc, New York.

Hadi, 2000, Mekanika Struktur Komposit, Direktoral P3M Dirjen Dikti Depdiknas, Jakarta.

Hartomo,A.J., Rusdiarsono, A., Hardianto, D., 1992, Memahami Polimer dan Perekat, Andi Offset. Yogyakarta.

Ismoyo, 1994, Karakteristik kekuatan bending komposit berpenguat kombinasi serat kenaf acak dan anyam. Universitas Muhamadiah, Malang.

Justus Sakti Raya., 2001, Technical Data Sheet, Jakarta.

Khanam,2007, Tensile, Flexural and Compressive Properties of Sisal/Silk Hybrid Composites, Journal of Reinforced Plastics and Composites, 1065-1069

Khoatane, M. C2008. Hemp Fiber-Reinforced Pentene/Polypropylene Copolymer: The Effect of Fiber Loading on the Mechanical and Thermal Characteristics of the Composites, Journal of Reinforced Plastics and Composites,vol.27, hal. 1533.

Lokantara, P., dan Suardana, N.P.G., 2007, Analisis Dan Perlakuan Serat Tapis Serta Rasio Epoxy Hardener Terhadap Sifat Fisis Dan Mekanis Komposit Tapis/Epoxy, Jurnal IImiah Teknik Mesin CAKRAM
Vol.1 No.1, Universitas Udayana, Bali

Murray, 1999, Terobosan baru memperkecil kandungan karbondioksida di udara menggunakan stek daun lidah mertua. Universitas Muhamadiah, Malang.

Mohammad Romi (2003), Tugas Akhir Jurusan Teknik Mesin, Universitas Mataram.

Profesor Jamasri, Tim reviewer monitoring dan evaluasi PKM 2012, Yogyakarta.

Purwanto (2006) ,Tugas Akhir Jurusan Teknik Mesin, Universitas Mataram.

Richardson, J. T. E., Eysenck, M. W., and Warren Piper, D. (eds) (1987). Student Learning: Research in Education and Cognitive Psychology. Milton Keynes: SRHE \& Open University Press.

Rizvi F. B., Rashed., 2006, Effects Of Process Parameters On Tensile Strength Of Jute Fiber Reinforced Thermoplastic

Composites, Department of Materials and Metallurgical Engineering, Bangladesh University of Engineering and Technology, Dhaka -1000, Bangladesh. Journal of Naval Architecture and Marine Engineering Juni, 2006

Sabari, Is., 2009, Pengaruh Fraksi Volume Serat Terhadap Kekuatan Tarik, Harga Impak Dan Kemampuan Serapan Bunyi Dari Komposit Serat Sabut Kelapa Anyaman 3D, Tugas Akhir, Universitas Muhammadiyah Surakarta

Satish, K. G., Siddeswarappa, B., Mohamed Kaleemulla, K., 2010, Characterization of In-Plane Mechanical Properties of Laminated Hybrid Composites., Journal of Minerals \& Materials Characterization \& Engineering., Department of Mechanical Engineering, University B.D.T. College of Engineering and Davangere Department of Industrial and Production 
Engineering, University B.D.T. College of Engineering, Davangere 577004, India.

Schwartz, M.M., 1984, Composite Materials Handbook, McGraw-Hill Book Co., New York.

Siriwardena, S., Ismail, H., Ishiaku, U.S. 2003, A Comparison of the Mechanical Properties and Water Absorption Behavior of White Rice Husk Ash and Silica Filled Polypropylen Composites, Journal of Reinforced Plastics and Composites, vol. 22, hal.1645.
Sulistijono., 2008, Analisa Pengaruh Fraksi Volume Serat Kelapa Pada Komposit Matriks Polyester Terhadap Kekuatan Tarik, Impact Dan Bending, Tugas Akhir, ITS, Surabaya.

Supardi, 1999, Pengujian Logam, Angkasa Bandung, Bandung.

Tata sudira, dan Shinroku saito, 1985, Pengetahuan bahan teknik. PT. Prandnya Diaramita, Jakarta. 